\title{
Essential indicators for measuring area-based conservation effectiveness in the post-2020 global biodiversity framework
}

Authors: Jonas Geldmann ${ }^{1,2,3 *}$, Marine Deguignet ${ }^{4}$, Andrew Balmford ${ }^{2}$, Neil D. Burgess ${ }^{4,1,2}$, Nigel Dudley ${ }^{5}$, Marc Hockings ${ }^{6}$, Naomi Kingston ${ }^{4}$, Helen Klimmek ${ }^{4}$, Alanah Hayley Lewis ${ }^{1}$, Carsten Rahbek ${ }^{1}$, Sue Stolton ${ }^{5}$, Claire Vincent ${ }^{4}$, Sue Wells ${ }^{7}$, Stephen Woodley ${ }^{8}$ James E. M. Watson ${ }^{6,9}$

\section{Affiliations}

1 Center for Macroecology, Evolution and Climate, Globe institute, University of Copenhagen, Copenhagen, Denmark

2 Conservation Science Group, Department of Zoology, University of Cambridge, Downing St., Cambridge CB2 3EJ, United Kingdom

3 International Union for Conservation of Nature, World Commission on Protected Areas Management Effectiveness Specialist Group, United Kingdom

4 United Nations Environment Programme World Conservation Monitoring Centre, 219 Huntingdon Road, Cambridge, CB3 ODL, United Kingdom

5 Equilibrium Research, Bristol BS1 6UQ, United Kingdom

6 Centre for Biodiversity and Conservation Science, The University of Queensland, Brisbane, QLD, 4072, Australia

7 International Union for Conservation of Nature's World Commission on Protected Areas, Marine Management Effectiveness Task Force, United Kingdom

8 International Union for Conservation of Nature, World Commission on Protected Areas, Switzerland

9 Global Conservation Program, Wildlife Conservation Society, 2300, Southern Boulevard, Bronx, NY, USA

Keywords: 2011-2020 Strategic Plan for Biodiversity; Biodiversity Outcomes; Indicators; Management effectiveness; Other Effective Area-based Conservation Measures; post-2020; Protected areas

*Corresponding author: Jonas Geldmann Mail: igeldmann@sund.ku.dk phone: +45 29905192

\begin{abstract}
Work has begun in earnest to formulate a post-2020 Global Biodiversity Framework which will outline the vision and targets for the next decade of biodiversity conservation and beyond. However, the performance of the 2011-2020 Strategic Plan for Biodiversity suggests that even a meaningful target can fail to deliver if not accompanied by fit-for-purpose indicators. Here we provide a review of how 'protected area' effectiveness was addressed in the 2011-2020 plan and based on this, provide recommendations for fit-for-purpose indicators that will measure how such efforts contribute to the conservation of biodiversity. Indicators need to be built on quantitative data from site-level biodiversity monitoring of species and ecosystems combined with measurements of the state of nature in near-time, informed by remote-sensed products and other technologies. Additionally, indicators need to capture whether the essential elements of good management are in place including the identification of ecological values, threats, and objectives, equitable governance, and sufficient management resources and capacity. These fit-for-purpose indicators will require multilateral collaboration to galvanize support for, and resources to develop, the necessary infrastructure to collate and store information from countries.
\end{abstract}




\section{Introduction}

The United Nation's Strategic Plan for Biodiversity 2011-2020, developed under the Convention on Biological Diversity ( $C B D$ ) and endorsed by all the biodiversity-related conventions, has been the main instrument of the international community's commitment to reverse biodiversity loss over the past decade (Rogalla von Bieberstein et al. 2019). Essential to the achievement of this Plan are the 20 Aichi Targets, of which Target 11 focuses on in situ conservation through Protected Areas (PAs) and Other Effective Area-based Conservation Measures (OECMs) (Convention on Biological Diversity 2010). PAs today cover $15.1 \%$ of Earth's land surface and $7.9 \%$ of the oceans (UNEP-WCMC and IUCN 2020), and the establishment of over 100,000 new PAs over the last decade is celebrated by some as a major political achievement - especially in comparison to the other Aichi Targets. However, essential elements of Target 11 other than coverage have seen much less progress. For example, Target 11 called for particular attention to protecting areas of importance for biodiversity and ecosystem services - many of which remain unprotected (Butchart et al. 2015), and with more recently established PAs failing to narrow this gap (Maxwell et al. 2020). There is, however, evidence that many more areas of importance to biodiversity are covered by OECMs but not yet documented (Donald et al. 2019). More importantly, PAs remain chronically underfunded and understaffed (Coad et al. 2019; Gill et al. 2017). As a consequence, many of the world's PAs are not delivering the biodiversity outcomes expected of them and outlined in Target 11 (Amano et al. 2018; Barnes et al. 2016a; Geldmann et al. 2019). This has led some to call into question the success of governments in implementing Aichi Target 11 as a conservation action to safeguard biodiversity (Barnes et al. 2018; Visconti et al. 2019).

Work has begun in earnest to formulate the vision and targets for the next decade of biodiversity conservation and beyond. A key step was the release in January 2020 of the zero draft text of the Post2020 Global Biodiversity Framework (Convention on Biological Diversity 2020). This lays out an ambitious plan for achieving the 2050 shared vision of "living in harmony with nature" and introduces a theory-of-change to operationalize the path forward that explicitly recognizes the scope of the challenge and the need for transformational change. Importantly, the initial draft has retained a standalone target on PAs and OECMs: "Protect sites of particular importance for biodiversity through protected areas and other effective area-based conservation measures, by 2030 covering at least [60\%] of such sites and at least [30\%] of land and sea areas with at least [10\%] under strict protection". However, regardless of the specific formulation of a new area-based target, working out how best to measure progress and determining what constitutes effective site-based conservation is now essential. The lack of a clear definition and operational indicators have been identified as core shortfalls in the 2011-2020 Strategic Plan for Biodiversity (Maxwell et al. 2020), and Parties to the CBD have requested that new targets are linked to viable indicators before the targets are agreed in October 2020. 
Here we provide a review of how effectiveness was addressed in the 2011-2020 strategic plan and, using this, identify a number of key shortfalls. Based on this, we provide recommendations for suitable indicators for measuring area-based conservation effectiveness for the post-2020 Global Biodiversity framework, that aim to ensure that a target on PAs and OECMs is fit-for-purpose and contributes to the conservation of biodiversity in the decades to come.

\section{Learning from the 2011-2020 strategic plan}

Most assessments of progress towards achieving Aichi Target 11 were based on PA coverage and the quantitative benchmarks of $17 \%$ of terrestrial and inland water areas and $10 \%$ of coastal and marine areas to be protected by 2020. One reason for this is that the World Database on Protected Areas (WDPA) has facilitated collation of data on PA extent, enabling countries and scientists to measure and report progress towards the coverage element of Target 11 (UNEP-WCMC and IUCN 2020). The spatial attributes of PAs captured in the WDPA have also allowed assessments of PAs in relation to ecological representation, coverage of some areas of importance for biodiversity, connectivity, and the potential contribution of PAs to the maintenance of some ecosystem services (Gannon et al. 2019; Maxwell et al. 2020; UNEP-WCMC and IUCN 2020). However, capturing information on the effectiveness of PAs has remained challenging (Coad et al. 2015), with the CBD providing no globally consistent advice for this element of Target 11. A Global Database on Protected Area Management Effectiveness (GD-PAME) was developed as the official repository for reporting on PA effectiveness to the CBD but, like many indicators used by the $\mathrm{CBD}$, it has been populated with data that were not specifically collected for use as an indicator for Target 11 and are only available for a sub-set of sites (ca. 10\% of PAs in the WDPA; UNEP-WCMC and IUCN 2020). In addition, GD-PAME only records whether an assessment of management effectiveness has been undertaken - with no information about whether the PA is effective in terms of biodiversity outcomes. This is analogous to measuring progress on poverty alleviation by counting the number of people with a bank account rather than whether they have the resources necessary to sustain themselves.

We recognize that reporting on management effectiveness is far more difficult than reporting the area under protection, a situation not helped by the lack of standardisation of effectiveness indicators and guidance from the CBD on how to apply these. This has resulted in a range of different approaches and methodologies for assessing management effectiveness being applied across the world (Coad et al. 2015). This may not necessarily be bad in terms of delivering improved outcomes; indeed, an essential element of assessing the effectiveness of PAs and OECMs is to improve adaptive management practices at all sites, using systems that are customised to local situations and contexts (Hockings et al. 2006). Simply knowing that an assessment has been done can, thus, provide some information. However, the diversity of approaches applied across the world has made comparing across methods and collating data 
for reporting towards the 2011-2020 Strategic Plan very difficult (Gannon et al. 2019). As a result, we do not know if the PA estate is achieving its conservation objectives. Therefore, an important lesson from the past 10 years of assessing progress towards Aichi Target 11 is that there is an urgent need for flexible country-based indicators of PA biodiversity outcomes that are sensitive to local conditions and capacity but which at the same time can be used to report on collective progress towards global targets.

\section{Putting outcomes at the centre of measuring effectiveness}

Documenting the delivery of biodiversity outcomes must be an explicit part of any future area-based target if PAs and OECMs are to play their intended role in diminishing human pressures on nature. Importantly, this means that well designed indicators of biodiversity outcomes are essential which is not the case for Target 11 . To capture the complexity of biodiversity outcomes we see the need for a two-pronged approach.

First, we need globally consistent indicators of change in the state of biodiversity, building on the impressive advances made in remote sensing and other technologies. In selecting remote-sensed indicators, appropriate resolution in time and space, data quality, and open-access will be important. It will also be necessary to validate available data (as much of the data now coming online lack any quality control). For assessing changes at the site and regional scales, data need to be at a resolution of at least $1 \mathrm{~km}^{2}$ and preferably finer-scaled, capturing both ecological state (i.e. extent and integrity of ecosystems) and anthropogenic pressures, and should be updated every year (Joppa et al. 2016; Watson and Venter 2019). Such validated remote-sensed products would allow for an independent assessment of some aspects of the state of nature and changes over time in relation to our responses to mitigate the loss of biodiversity, thus minimizing subjective assessment by managers (Watson and Venter 2019). We recommend that the post-2020 Global Biodiversity Framework recognizes the mission-critical values of such remote sensed data and calls for the development of scientifically robust products towards this end. The satellites to deliver such data are already in orbit and existing efforts are providing a foundation to build on for near-future development of a comprehensive ecosystem-classification which goes beyond forests to cover all ecosystems and biomes - including freshwater and marine (Bland et al. 2019; Kissling et al. 2018).

Second, we recommend that these high quality remotely-sensed global indicators should be complemented by site-level indicators of the changing state of nature based on finer-scale biodiversity inventories that can capture changes that more coarse-scale remote sensed measures cannot (e.g. empty forest syndrome; Redford 1992). Site-level monitoring should capture the condition of key biodiversity elements for which the site is valued, ideally against a counterfactual reference value to allow for the assessment of impact (Baylis et al. 2016). The extent of site-level monitoring could vary depending on context and would not always need to cover all PAs and OECMs in a country, provided 
sampling designs are appropriate. In some cases, these assessments of site-level condition might be expert-based and connected to assessments of other management elements. But increasingly, new technology can also help to provide powerful data for strengthening management practices. For example, the SMART tool (designed to facilitate PA compliance and enforcement) is now used in over 750 sites across the world in collaboration with more than 115 government partners to help managers improve real-time responses to infractions based on high-quality data from camera-traps and audiorecorders, that can also be used to track the state of nature (SMART Partnership 2018). In addition, many countries have detailed site-monitoring schemes for biodiversity within PAs which, if linked together, could provide the basis for a global system to determine PA and OECM outcomes.

\section{Capturing data on effective planning and management to cut costs}

While delivering biodiversity outcomes is the fundamental goal of PAs and OECMs, assessing the efficacy and adequacy of management and planning are essential to understanding why some area-based conservation approaches are more effective than others (Mascia et al. 2017). This means we need to assess elements of effective management other than biodiversity outcomes so that we can learn from best practice and ensure that PAs and OECMs deliver biodiversity outcomes cost-effectively (Hockings et al. 2006). Ideally this would build on assessments that are already part of the management cycle and accounting in many countries. In Europe, for example, many countries have compiled a large amount of data and information on management effectiveness as well as biodiversity outcomes for use in national and EU level stocktaking. Similarly, in countries such as South Africa, India, Bhutan, Colombia and Indonesia, management effectiveness assessments are already a mandated part of official management processes to promote best practice and ensure cost-effective use and allocation of sparse resources. However, the absence of a fit-for-purpose global infrastructure, with clear workflows and processes, has prevented such site-level data from being used to track progress towards management effectiveness at the global scale. To ensure that the post-2020 framework results in effective biodiversity outcomes, it is logical both to require that sites are effectively managed, and also that their management effectiveness is regularly assessed. Parties of the CBD should prioritize the development of the necessary indicators and data-capture mechanisms so that countries can provide information on their efforts to make PAs and OECMs effective. Additionally, a well-structured global database, such as GD-PAME expanded to include qualitative data from assessments, can promote knowledge exchange and provide a common language for sharing best practices.

We recommend that management effectiveness indicators for the next CBD Global Biodiversity Framework must capture the three key aspects that have been shown to correlate with site management effectiveness (Barnes et al. 2016b; Geldmann et al. 2018; Gill et al. 2017): one, whether a planning process to identify ecological values, threats, and objectives is in place; two, whether sufficient 
resources and capacity to implement the necessary management actions are available; and three, whether governance is equitable (e.g. all relevant stakeholders are fully involved in decision-making processes). The post-2020 framework must include indicators across these three elements to ensure that progress on the essential enabling conditions for success are captured and reported on by Parties to the CBD. The IUCN Green List for Protected and Conserved Areas standard provides a holistic framework that can help countries navigate this process (Hockings et al. 2019). This covers 1) Good governance - which will often be related more closely to the context of a PA or OECM than the site itself, 2) Sound design and planning, 3) Effective management, and critically, 4) Successful conservation outcomes. We are not suggesting that all PAs should work towards getting 'green-listed', but that the four pillars of the Green List Standard provide a conceptual foundation that should be used in developing indicators for the effectiveness of PAs and OECMs.

Management Effectiveness indicator information needs to be up-to-date and at a spatial level that corresponds with where and when management decisions are taken. We acknowledge that such information is often sensitive in that it is linked to funding opportunities or may be seen as critical of individual managers or agencies who often do outstanding work in very challenging socio-political and environmental contexts. Global databases can and should be managed to guard these site sensitivities. Score-card methods, where managers and other stakeholders collectively assess the effectiveness of management practices, are already applied widely across the world (Coad et al. 2013) allowing stakeholders to assess the adequacy of the key management elements. Such approaches can be adapted to national requirements and contexts. Whilst not without their challenges (Cook and Hockings 2011; Mascia et al. 2014) these methods have a long history and can, with training and support, be effective at capturing site- or PA network-level information (Fox et al. 2014; Stolton et al. 2019). While this information will often be most relevant at the site level, reporting might be more appropriate at the level of networks of sites or an entire country.

\section{Recommendations for beyond $\mathbf{2 0 2 0}$}

This year is critical in setting the agenda and ambitions for biodiversity conservation over the coming decade and beyond, and it will be crucial next year to roll out a system for measuring progress against that agenda using credible indicators. We urge that any area-based post-2020 target explicitly recognizes the urgent need to deliver biodiversity outcomes through sufficient resources and effective management, sound governance and proper planning and design. Importantly, this will also require the formulation and development of fit-for-purpose indicators that capture biodiversity outcomes as well as management effectiveness inputs. We recommend that such indicators build on quantitative information from site-level biodiversity monitoring that covers species and ecosystems in combination with remote-sensed products and other technologies that can provide an independent measure of the 
state of nature. Additionally, indicators need to capture management effectiveness covering good governance, sound design and planning, and effective management - the three additional pillars of the IUCN Green List.

To deliver fit-for-purpose indicators that can be used to drive improved conservation action, we believe that multilateral commitment is needed to bolster national level reporting. Thus, we strongly urge that Parties to the CBD come together to support existing efforts to develop high-quality and freely available remote-sensed products that can track changes in conservation outcomes. These need to be rolled out from 2021 and for the next 10 years to 2030 to measure progress towards the next global plan for biodiversity and can also help with reporting towards the Sustainable Development Goals. Similarly, support for and resources to develop a digital infrastructure - potentially building on the existing GDPAME and linked to the WDPA - aiming to collate and store information on management and governance from Parties to the $\mathrm{CBD}$ - will be vital. If these elements are put in place, we will be in a strong position to assess progress, and take corrective action, to ensure that area-based conservation measures are delivering the outcomes that the world needs.

International policy efforts have evidently had significant positive impacts on biodiversity (IPBES 2019). Nevertheless, it is equally clear that far greater efforts are now urgently required to bend the curve of current global biodiversity declines into biodiversity gains by 2030. Inter-governmental commitments to ambitious targets and resources will be key but, so too, we believe, is the development and adoption of fit-for-purpose indicators for tracking progress on their delivery.

\section{Acknowledgements}

This work is supported by Aage V. Jensen Naturfond.

\section{References}

Amano T., Székely T., Sandel B. et al. (2018) Successful conservation of global waterbird populations depends on effective governance. Nature 553, 199-202.

Barnes M., Craigie I.D., Harrison L. et al. (2016a) Wildlife population trends in protected areas predicted by national socio-economic metrics and body size. Nature communications 7, 12747.

Barnes M.D., Craigie I.D., Dudley N., Hockings M. (2016b) Understanding local-scale drivers of biodiversity outcomes in terrestrial protected areas. Annals of the New York Academy of Sciences.

Barnes M.D., Glew L., Wyborn C., Craigie I.D. (2018) Prevent perverse outcomes from global protected area policy. Nature Ecology \& Evolution, 1-4.

Baylis K., Honey-Rosés J., Börner J. et al. (2016) Mainstreaming Impact Evaluation in Nature Conservation. Conservation Letters 9, 58-64.

Bland L.M., Nicholson E., Miller R.M. et al. (2019) Impacts of the IUCN Red List of Ecosystems on conservation policy and practice. Conservation Letters 12, e12666.

Butchart S.H.M., Clarke M., Smith B. et al. (2015) Shortfalls and solutions for meeting national and global protected area targets. Conservation Letters 8, 329-337.

Coad L., leverington F., burgess N.D. et al. (2013) Progress towards the CBD Protected Area Management Effectiveness Targets. Parks 19, 13-24. 
Coad L., Leverington F., Knights K. et al. (2015) Measuring impact of protected area management interventions: current and future use of the Global Database of Protected Area Management Effectiveness. Philosophical Transactions of the Royal Society of London B $\mathbf{3 7 0 .}$

Coad L., Watson J.E.M., Geldmann J. et al. (2019) Widespread shortfalls in protected area resourcing significantly undermine efforts to conserve biodiversity. Frontiers in Ecology and the Environment 17, 259-264.

Convention on Biological Diversity. (2010) Decision X/2: Strategic Plan for Biodiversity 2011-2020. Convention on Biological Diversity, Nagoya, Japan.

Convention on Biological Diversity. (2020) Zero draft of the post-2020 global biodiversity framework. p. 15. Convention on Biological Diversity, Kunming, China.

Cook C.N., Hockings M. (2011) Opportunities for improving the rigor of management effectiveness evaluations in protected areas. Conservation Letters 4, 372-382.

Donald P.F., Buchanan G.M., Balmford A. et al. (2019) The prevalence, characteristics and effectiveness of Aichi Target 11's "other effective area-based conservation measures" (OECMs) in Key Biodiversity Areas. Conservation Letters 12, e12659.

Fox H.E., Holtzman J.L., Haisfield K.M. et al. (2014) How Are Our MPAs Doing? Challenges in Assessing Global Patterns in Marine Protected Area Performance. Coastal Management 42, 207-226.

Gannon P., Dubois G., Dudley N. et al. (2019) An update on progress towards Aichi Biodiversity Target 11. Parks 25, 7-18.

Geldmann J., Coad L., Barnes M.D. et al. (2018) A global analysis of management capacity and ecological outcomes in terrestrial protected areas. Conservation Letters, e12434.

Geldmann J., Manica A., Burgess N.D., Coad L., Balmford A. (2019) A global-level assessment of the effectiveness of protected areas at resisting anthropogenic pressures. Proceedings of the National Academy of Sciences, 201908221.

Gill D.A., Mascia M.B., Ahmadia G.N. et al. (2017) Capacity shortfalls hinder the performance of marine protected areas globally. Nature 543, 665-669.

Hockings M., Hardcastle J., Woodley S. et al. (2019) The IUCN Green List of Protected and Conserved Areas: Setting the standard for effective area-based conservation. Parks 25, 57-66.

Hockings M., Stolton S., Leverington F. et al. (2006) Evaluating Effectiveness: A framework for assessing management effectiveness of protected areas. p. 105. International Union for Conservation of Nature, Gland, Switzerland.

IPBES. (2019) The IPBES Global Assessment on Biodiversity and Ecosystem Services. IPBES, Bonn, Germany.

Joppa L.N., O'Connor B., Visconti P. et al. (2016) Filling in biodiversity threat gaps. Science 352, 416-418.

Kissling W.D., Ahumada J.A., Bowser A. et al. (2018) Building essential biodiversity variables (EBVs) of species distribution and abundance at a global scale. Biological Reviews 93, 600-625.

Mascia M.B., Fox H.E., Glew L. et al. (2017) A novel framework for analyzing conservation impacts: evaluation, theory, and marine protected areas. Annals of the New York Academy of Sciences 1399, 93-115.

Mascia M.B., Pailler S., Thieme M.L. et al. (2014) Commonalities and complementarities among approaches to conservation monitoring and evaluation. Biological Conservation 169, 258-267.

Maxwell S.L., Cazalis V., Dudley N. et al. (2020) Area-Based Conservation in the 21st Century. Preprints.

Redford K.H. (1992) The Empty Forest. Bioscience 42, 412-422.

Rogalla von Bieberstein K., Sattout E., Christensen M. et al. (2019) Improving collaboration in the implementation of global biodiversity conventions Conservation Biology 33, 821-831.

SMART Partnership. (2018) SMART partnership annual report 2018. p. 46. SMART Partnership, New York, USA.

Stolton S., Dudley N., Belokurov A. et al. (2019) Lessons learned from 18 years of implementing the Management Effectiveness Tracking Tool (METT): a perspective from the METT developers and implementers. PARKS 25, 79-92.

UNEP-WCMC and IUCN. (2020) The World Database on Protected Areas (WDPA) January 2020. in U.-W.a. IUCN editor. UNEP-WCMC and IUCN, Cambridge, UK.

Visconti P., Butchart S.H.M., Brooks T.M. et al. (2019) Protected area targets post-2020. Science 364, $239-241$.

Watson J.E.M., Venter O. (2019) Mapping the Continuum of Humanity's Footprint on Land. One Earth 1, 175-180. 